\title{
Toluene concentrations reduction by using photocatalytic coating methods for cementitious materials
}

\author{
Ayat Hussein ${ }^{1, *}$, Riyad Al Anbari ${ }^{1}$ and Maan Hassan ${ }^{1}$ \\ ${ }^{1}$ Building and Construction Engineering Department., University of Technology (10066), Baghdad, Iraq.
}

\begin{abstract}
Volatile organic compounds (VOC) generated from various sources like car combustion is one of the most surrounding pollutants, which can be transferred from one form to another in the presence of sunlight. In the present work the ability of the reduction of VOC have been conducted on cementitious samples surfaces by using toluene as a pollutant gas and $\mathrm{TiO} 2$ as an environmentally friendly photocatalyst . Two coating methods have been used (dip and spray) with two types of aqueous solution, prepared by spreading $3 \mathrm{~g} / \mathrm{L}$ micro and nano $\mathrm{TiO} 2$ powder with deionized water. A laboratory test procedure was adopted to assess the performance of the coated specimens. The specimens were subjected to toluene gas and there efficiency in gas removal was monitored with time. Furthermore, contact angle for the coated samples was also examined to investigate the hydrophilicity of the coated substrate. The results showed that $\mathrm{TiO} 2$ give high activity and work as a good photocatalyst for mitigation of air pollutants, and that it could be used in different ways and concentrations to obtain better air quality and aesthetic building appearance. The observed coating efficiency in reducing the toluene was more pronounced in higher than lower gas concentrations for the micro coated samples with removal efficiency equals to $13 \%$ and $10 \%$ for dipping and spraying method, respectively. While the higher removal was about $20 \%$ for both nano dipping and nanospray methods for the inlet gas concentration 3ppm. This behavior reflects the beneficial effects of $\mathrm{TiO} 2$ coating procedure in highly pollutant environments, like Iraq.
\end{abstract}

\section{Introduction}

Air pollution is one of the most harmful environmental problems that effects human health (Boyd 2006). Recent studies showed that photocatalytic materials can be used with concrete building through surface coatings or mixing with

Semiconductors used for the degradation of pollutants are usually metal oxides or metal sulfides. In searching for the ideal photocatalyst in remediation of organic pollutants by using sunlight, several considerations must be taken; chief among them are energy of the band gap and oxidation potential (Hathway 2009).

$\mathrm{TiO}_{2}$ considered one of the most active photocatalyst which has three main crystal forms: anatase, rutile, and brookite. Anatase and rutile are the main two crystals which show photocatalytic activity. For photocatalytic applications, anatase has been considered to be more active than rutile because the conduction band location for anatase is more favorable for driving conjugate reactions involving electrons.(Zhao \& Yang 2003)

*Corresponding author : 40128@uotechnology.edu.iq building materials. In the presence of UVlight and photocatalyst material, oxidation of the pollutants started and precipitated on the surface of the material. The products of the reaction are washed from the surface by rain. (Beeldens 2006).

The widely use of $\mathrm{TiO}_{2}$ as a photocatalytic with building materials is due to the following characteristics(Chen \& Poon 2009): a) Effective, inexpensive, safe, and have chemical stability, b) It has high photocatalytic activity compared with other photocatalysts metal oxide, c) Compatible with building materials.

The utilization of the photocatalytic building materials began from 1990s(Fujishima \& Zhang 2006). Recently, one of the most effective ways to apply $\mathrm{TiO}_{2}$ is by adding a thin coating to the weathering layer. If this layer is partly used by bad weather conditions a new coating of titanium dioxide particles could be added to the surface (Beeldens 2006). There are various types of substrates as supporting materials that could be used for applying $\mathrm{TiO}_{2}$ to reduce air pollutants. More interests are growing for using cementitious 
materials (e.g. mortar and concrete or cement paste) because of their porous structures and high binding property(Chen et al. 2011).

Studies reported lower photocatalytic activity of $\mathrm{TiO}_{2}$ when using in immobilized form while the suspended form was more efficient (Rachel et al. 2002).

Finishing sprayed coating for wide horizontal and vertical surfaces, like ceiling, walls, tunnel archs and multi-story car parks were began to be used significantly(Marco et al. 2013).

Coatings must be protective barrier against chemical attack, abrasion, in addition to aesthetics aspects. Interface performance between film and substrate material takes an important part in the durability of the whole system. (Balaguru \& Chong 2008).

Applying coating solutions are interesting because of the surface photocatalysis reaction, furthermore lead to lower consumption of $\mathrm{TiO}_{2}$ (Martinez et al. 2011) and (Granqvist 2013). (Martinez et al. 2011) stated that there is a relation with the optimal $\mathrm{TiO}_{2}$ content corresponded to the maximal photocatalytic surface area accessible to polluting substances.

Most solids are naturally rough; however, superhydrophilic surface coating could be obtained by chemical treatment or deposited in submicroscopic particles. Films of nanoparticles are often deposited on substrates from solutions/suspension, ink-jet printing, by a sol-gel dip technique, spin coating or through sputtering and spray coatings (Chen et al. 2011) and (Drelich et al. 2011). Other researchers, (Guo \& Poon 2012) compared $5 \%$ nano- $\mathrm{TiO}_{2}$ intermixed mortars with dip-coated mortars in nano- $\mathrm{TiO}_{2}$ solution; dip-coated mortars displayed a highly improved photocatalytic activity.

(Faraldos et al. 2016) stated that all of the sols (aqueous suspensions of nanoparticles) coatings showed very high affectivity, even when the coatings were extremely thin or diluted, independently on the deposition method (spraying or dip coating).

Time scale for dip coating method is slow, also this method has a mechanical and environmental stability, while spray coating method is rapid, have moderate stability, fast and easy reparability (Liu et al. 2016).

(Ramirez et al. 2010) concluded high toluene removal efficiencies (up to $86 \%$ ) obtained with the dip-coated samples, solution of $\mathrm{TiO}_{2}$ was by using a suspension of ethanol and $\mathrm{TiO}_{2}(0.05 \mathrm{~g} / \mathrm{ml})$.

(Hassan et al. 2012) compared removal efficiency for three types of coatings: thin film of concrete surface with $3 \%$ and $5 \% \mathrm{TiO}_{2}$ mixtures, nano $\mathrm{TiO}_{2}$ powder sprinkled to fresh concrete surface before hardening, and spraying a water based $\mathrm{TiO}_{2}$ on a hard concrete surface. Results obtained appears that $5 \% \mathrm{TiO}_{2}$ mixture and spraying water based $\mathrm{TiO}_{2}$ were the most efficient in removing pollutants from air stream.

Studies showed that the photocatalytic degradation of VOCs is dependent on both the air humidity and the initial concentration of pollutant (Martinez et al. 2011) . Toluene removal has been investigated by (Demeestere et al. 2008), using $\mathrm{TiO}_{2}$ coatings with particle sizes of $30-60 \mathrm{~nm}$ and a specific surface area larger than $250 \mathrm{~m}^{2} / \mathrm{g}$, demonstrating the effect of increasing RH (1-77\%) with increasing [TOL] in concentrations. Results revealed lower toluene removal efficiencies at higher $\mathrm{RH}$ and [TOL]in, whereas a positive effect was observed with increased $t$.

The aim of this research work is to evaluate the ability of nano scale $\mathrm{TiO}_{2}$ for the removal of toluene from surrounding air by applying two economic surface coating methods (spraying and dipping) that could be used even for previously constructed buildings. The performance of the coated cementitious specimens were assessed and then compared with the control, non-coated specimens.

\section{Materials and experimental procedure}

Concrete substrates were prepared according to ASTM C305 standards (ASTM C305 2011) standards. Cement used was type I ordinary portland cement, sand was graded according to ASTM C778 (ASTM C778 2002). Two grain size of commercial titanium dioxide powder was used; the first type is micro size range $(150-200 \mathrm{~nm})$ from Tianjin Zhi Yuan ReagentCo.,Ltd.-Chinese market with specific surface area of $6.9 \mathrm{~m}^{2} / \mathrm{g}$, the second type is nano size PC105 $(20 \pm 5 \mathrm{~nm})$ with specific surface area of $85.6 \mathrm{~m}^{2} / \mathrm{g}$ from Cristal Active Millennium SASFrance.

Pollutant gas used was from mesa specialty gases and equipment -USA, California. Concentration of toulene was $400 \mathrm{ppm}$ which diluted by another air cylinder $\left(80 \% \mathrm{~N}_{2}\right.$ and $\left.20 \% \mathrm{O}_{2}\right)$.

Gas detector device was from RAE system by Honeywell-USA, San Jose, detection limits for VOCs were from 1 to $1000 \mathrm{ppm}$. Parts for reactor details were collected from local market and designed according to International Organization for Standardization (ISO 22197-1:2007) with some modification according to test requirements. Two inlet toluene gas concentrations were applied on the coated samples $3 \mathrm{ppm}$ and $5 \mathrm{ppm}$ in order to study the effect of low and high gas concentrations on the removal efficiency. Tests parameters (humidity, temperature and light intensity) were the same for all samples. Minimum residence time of $60 \mathrm{~min}$ was used for all samples to investigate toluene concentration reduction. If reduction happened for a sample another $60 \mathrm{~min}$ was added to note if there is any more reaction happened.

\subsection{Mortar (subatrate) preparation}


Sand was sieved by using 4 sets of sieves and standard sand gained by using the retained on sieve $600 \mu \mathrm{m}$ according to ASTM C778.

Mixing procedure was conducted according to ASTM C305 standards with cement to sand ratio of $1: 2.75$ and $w / c$ of 0.484 . Flow test was made to ensure workability for the mixture (ASTM:C143713 2013). All mortar specimens were casted in $9 \mathrm{~cm}$ diameter petri dish to form $6 \mathrm{~mm}$ thickness samples and let harden for $24 \mathrm{hr}$ at room temperature then cured for 28 days at $100 \%$ relative humidity, then dried and stored in sealed bags.

\subsection{Aqueous solution preparation}

Samples have been coated by using two methods (spray and dip coating).Two types of titanium powder were used nano and micro, aqueous solutions for both types prepared on the same concentration. A suspension was prepared by spreading $3 \mathrm{~g} \mathrm{TiO}_{2}$ powder in $250 \mathrm{ml}$ ethanol and $750 \mathrm{ml}$ deionized water stirred for $(30 \mathrm{~min}$.) then ultrasonicated for 1 hour to obtain solution homogeneity.

In spray method, substrates were sprayed for 5 minutes by using spray pyrolysis equipment, (Fig. 1).

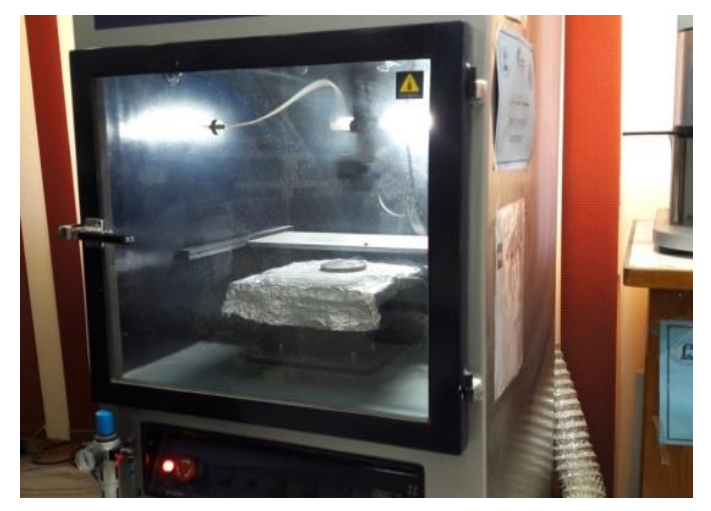

Fig. 1. Spray pyrolysis equipment

In dip coating method substrates were dipped in the same concentration of the aqueous solution for 10 minutes, and then dripped for 3 minutes (Fig. 2). Finally, for both methods samples were oven-dried at $105^{\circ} \mathrm{C}$ for 1 hour, and kept sealed till test (Fig. 3).

\subsection{Reactor setup}

Rectangular chamber used with dimensions of about $(30 \mathrm{~cm} \times 10 \mathrm{~cm})$, as shown in Fig. 4. All Tests were carried out at room temperature with applying a continuous air flow, gas flow used was about $1.6 \pm 0.2 \mathrm{l} / \mathrm{min}$. Two $6 \mathrm{~W}$ UV lamps have been used with intensity of $19 \mathrm{~W} / \mathrm{m}^{2}$ for each lamp and wave

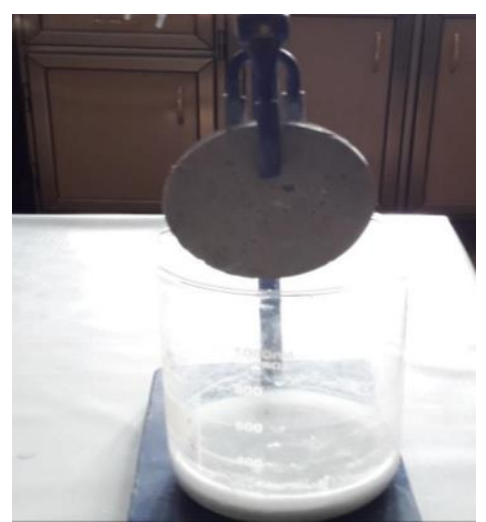

Fig. 2. Dipping method for spraying micro and nano $\mathrm{TiO}_{2}$ aqueous solutions

length range (300-400 $\mathrm{nm})$. To control humidity inside the reactor a humidifier has been used with control valves. Test procedure was as follows:

1- Calibration for the gas detector must be checked.

2- Putting the sample inside chamber and close tightly.

3- A continuous air flow ejected inside the reactor for about $1 \mathrm{hr}$ to persuade cleaning of the reactor especially VOC with UV lamps turned off and dark conditions.

4- Inlet gas pollutant (toluene) was opened and calibrated till reached the desired concentration 3 ppm and 5 ppm.

5- Humidity was calibrated through control valves to obtain RH of about $50 \%$.

6- Waiting for about $25 \mathrm{~min}$ to ensure chamber saturation and readings stabilization after this UV source is turned on.

7- The reaction continued till reaching a steady state.

8- After this UV is turned off, close the pollutant gas valve and again only air flow is ejected inside chamber.

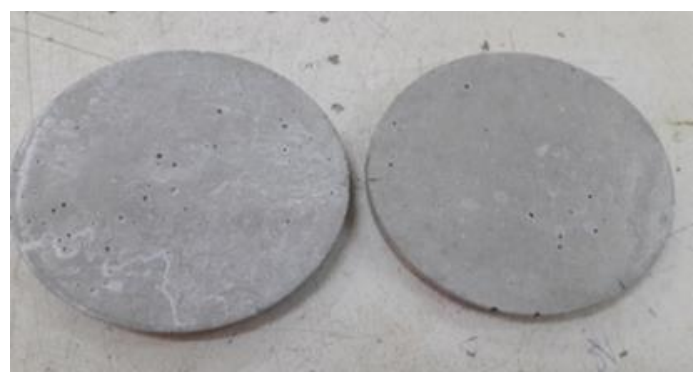

Fig. 3. Samples after spraying and dried (right) and after dipping and drying (left) 


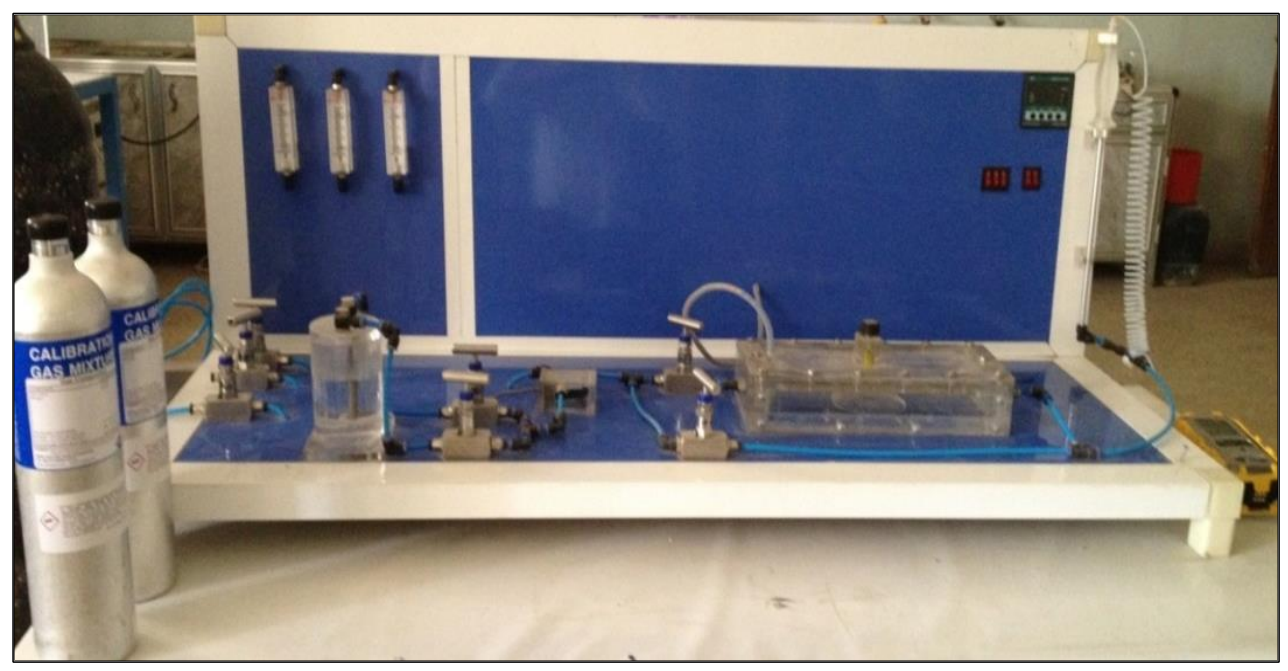

Fig. 4. Lab. Photocatalytic Reactor

\section{Results and discussion}

Tests were made to evaluate the suitability of the samples for VOC mitigation and the hydrophilicity of the coated samples was also investigated.

\subsection{Low VOC concentration reduction results by using dipping method}

Air flow meter was adjusted in order to obtain gas concentration equals to $3 \mathrm{ppm}$. There was no removal observed for toluene concentration from micro-dipped samples (Fig. 5). The removal for toluene for other samples was one value from the inert concentration $3 \mathrm{ppm}$ to $2 \mathrm{ppm}$ with differences in the time required for the reduction. Nano-dipped samples showed overall removal efficiency of $20.62 \%$ and the reduction happened after $37 \mathrm{~min}$. from starting the reaction (Fig. 6).

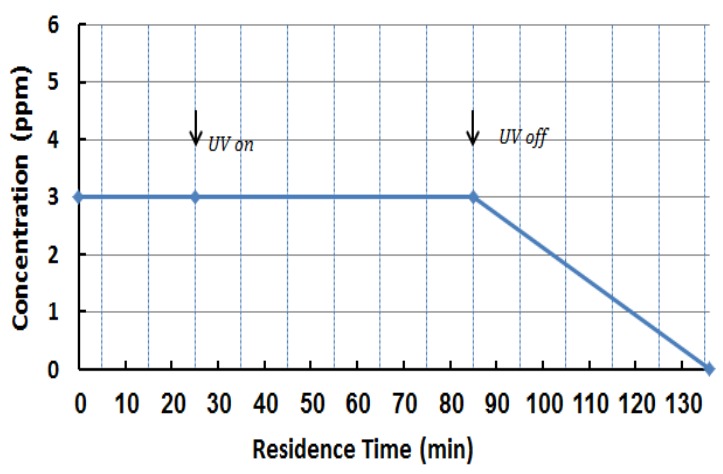

Figure 5- Micro-dipped sample reduction for low gas concentration

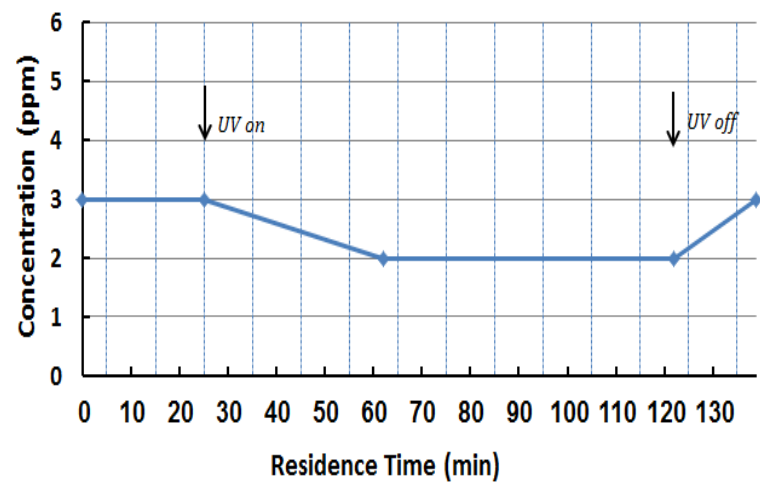

Figure 6- Nano-dipped sample reduction for low gas concentration

\subsection{High VOC concentration reduction results by using dipping method}

Adjusting flow meter for an inert gas concentration of $5 \mathrm{ppm}$, the removal for toluene was one value from the inert concentration $5 \mathrm{ppm}$ to $4 \mathrm{ppm}$ with differences in the time required for the reduction. Removal efficiency was $13.48 \%$ for micro-dipped samples after $29 \mathrm{~min}$ from reaction and $15 \%$ within $20 \mathrm{~min}$ for nano-dipped samples which indicates increasing susceptibility for the high gas concentrations rather than low gas concentrations as stated by (Martinez et al. 2011) especially for the micro-dipped samples; Figs. 7 and 8 show the obtained results for micro and nano-dipped samples, respectively. 


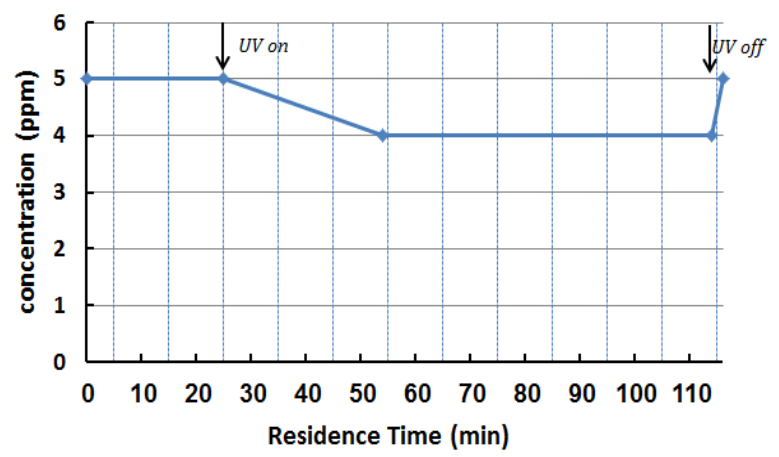

Figure 7- Micro-dipped samples reduction for high gas concentration

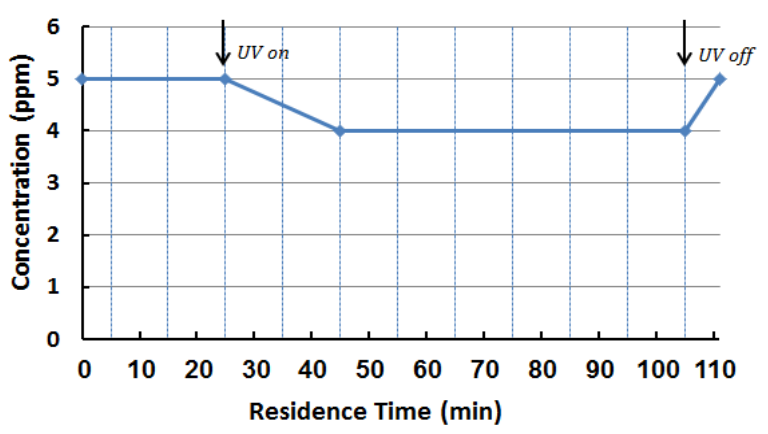

Figure 8- Nano-dipped samples reduction for high gas concentration

From the above results it could be concluded that the same range of removal happened but within different times, that is depending on the type of the material used. Nano coated samples required shorter time than micro coated sample. This result is expected due to the high surface area for the nano coated samples, which results to reduce time required for the reduction especially for high gas concentrations as stated by (Demeestere et al. 2008) and (Martinez et al. 2011) .

\subsection{Low VOC concentration reduction results by using spraying method}

The same test procedure in dipping method was applied on the previously micro and nano sprayed samples for 5 min spraying time.

Ejecting low gas concentration equals to $3 \mathrm{ppm}$ on micro-sprayed samples showed no gas removal. Nano-sprayed samples showed removal of $20.62 \%$, the reduction happened after $37 \mathrm{~min}$ from starting the reaction as shown in Fig. 9

\subsection{High VOC concentration reduction results by using spraying method}

5 min micro-sprayed samples showed removal of $10.16 \%$, the reduction happened after $58 \mathrm{~min}$ from

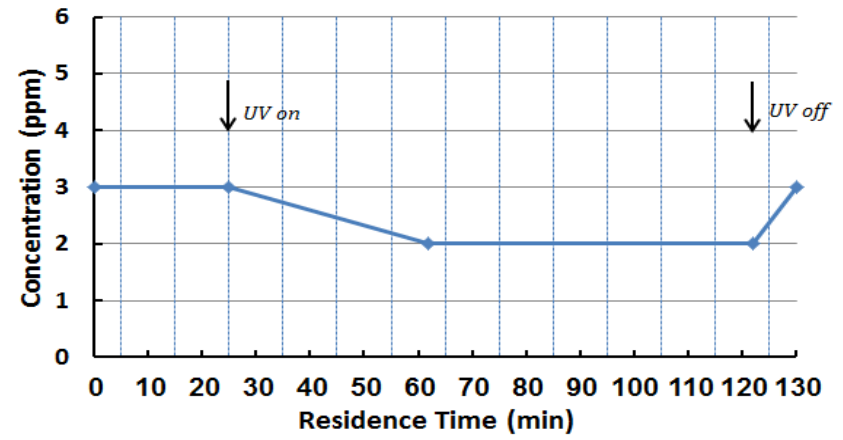

Figure 9- (5 min) Nano-sprayed samples reduction for low gas concentration

starting the reaction as shown in Fig.10. The removal requires less time for the $5 \mathrm{~min}$ nanosprayed sample that is equal to $15.79 \%$ and the reduction happened within $16 \mathrm{~min}$, Fig. 11. These results are expected due to high reactivity of nano coated samples.

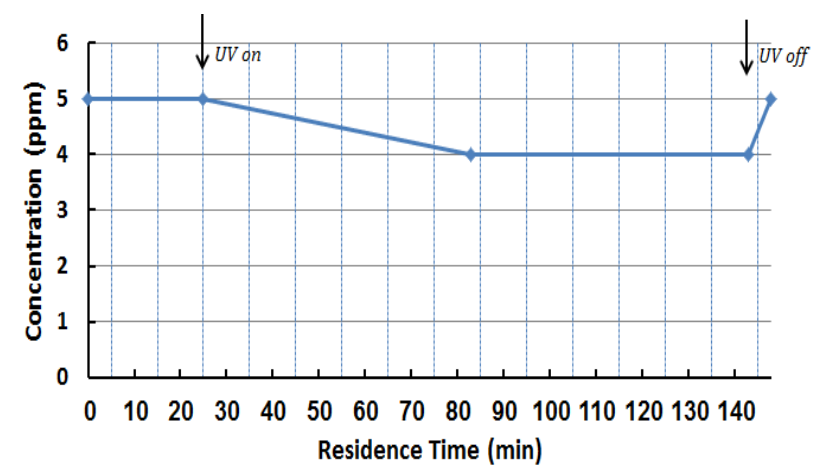

Figure 10- (5 min) Micro-sprayed samples reduction for high gas concentration

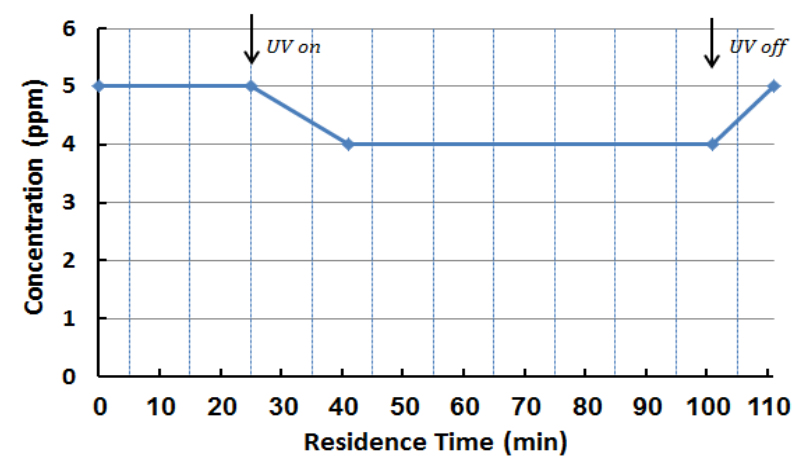

Figure 11- (5 min) Nano-sprayed samples reduction for high gas concentration

\subsection{Comparison between coating methods}

The removal of low toluene gas concentrations were not reduced by both micro-dipped and micro- 
sprayed samples, however, high gas concentrations were reduced.

Using the microTiO ${ }_{2}$ solution for removing toluene concentration by dipping method need less time with better removal than spraying method this could be explained due to the high amounts with large agglomerations of the particles that could be absorbed and bind to the substrate surface area, while in spray method some amounts of the solution adsorbed to the inner part of mortar substrate due to the small liquid particle volume generated by the spryer that could be inbounded by cement based material. This results in reducing the effective part for the coating and increasing time required for the removal.

For both nano-dip and 5 min nano-spray methods, the same removal for low toluene concentration was achieved within the same time (37 min).

For high toluene concentration removal, using nanoTiO $\mathrm{TiO}_{2}$ solution also seems to be almost within the same time for each spray and dip method 16 min and $20 \mathrm{~min}$, respectively. Fig. 12 illustrates the stated results.

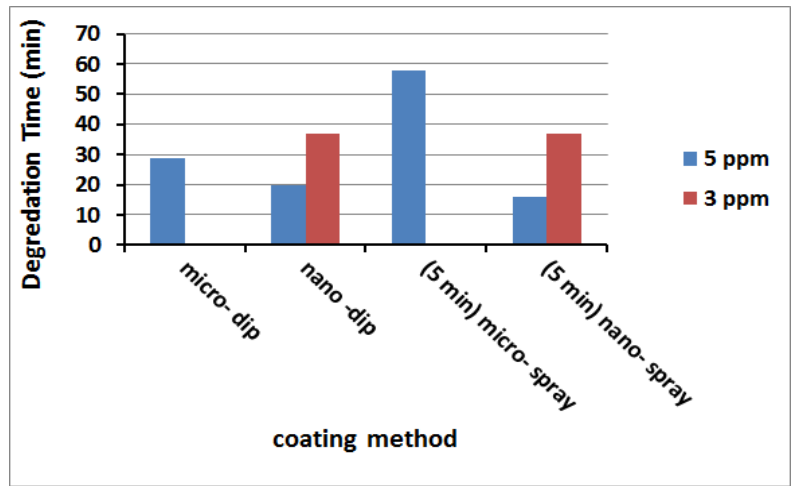

Figure 12- Comparison between coating method and time elapsed for toluene degradation

\subsection{Contact angle results}

Titanium dioxide have a hydrophilic specification, micro and nano dip coatings showed some agglomerations on the surface as expected, therefore substrates have a contact angle of about $34.7^{\circ}$ and $16.20^{\circ}$ for the micro and nano dip, respectively, also $5 \mathrm{~min}$ nano-sprayed samples have a contact angle equals to $14^{\circ}$ as shown in Fig. 13 , other coating types showed high hydrophilicity (superhydrophilic) surfaces with $0^{\circ}$ contact angle, Table 1 summarize the obtained results. Decreasing the hydrphilicity of the cementious material may helps in removing solid pollutants that adhere on surfaces by washing in addition to the photochemical reaction.

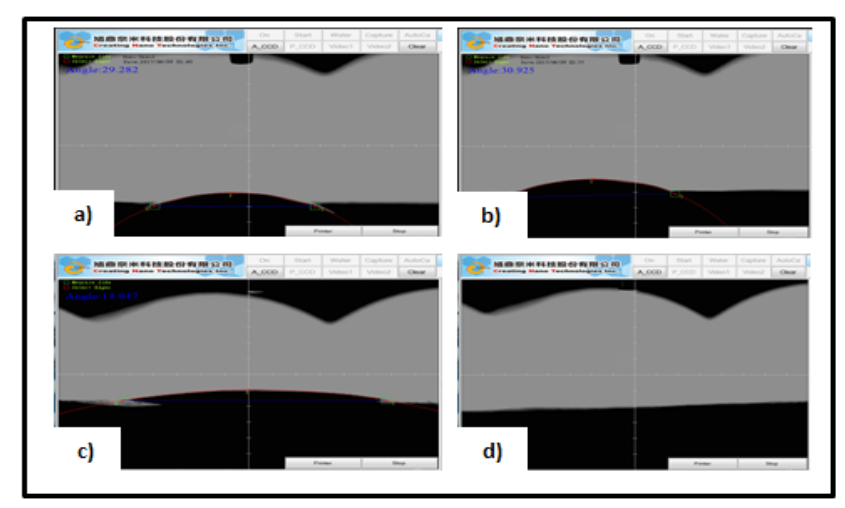

Figure13- Contacts angle image for various substrates; a) Micro -dipped substrate, b)Nano-dipped substrate) $5 \mathrm{~min}$ nano-sprayed substrate, d) Substrates with $0^{\circ}$ contact angle.

Table 1- Summary of contact angle test for the coated samples

\begin{tabular}{|c|c|c|}
\hline Sample Type & $\begin{array}{r}\text { Contact } \\
\text { Angle }\end{array}$ & Description \\
\hline $\begin{array}{c}\text { Reference mortar } \\
\text { sample }\end{array}$ & 0 & hydrophilic \\
\hline Micro dip & $34.7^{\circ}$ & hydrophilic \\
\hline Nano dip & $16.20^{\circ}$ & hydrophilic \\
\hline (5 min) micro-spray & 0 & hydrophilic \\
\hline (5 min) nano-spray & $14.04^{\circ}$ & hydrophilic \\
\hline
\end{tabular}

\section{Conclusions}

In this study, simple methods of spray or dip coating were adopted to assess the selfcleaning performance of the produced cementitious specimens. Based on the experimental work results in this investigation, the following conclusions can be drawn:

1. Coating cementitious materials with an aqueous solution contains nano titanium dioxide was effective in reducing toluene concentration.

2. Coatings with micro titanium dioxide were less efficient in the removal especially to the low gas concentration.

3. Both dip and spray coatings have the same activity in the removal when nano aqueous solution was used.

4. Coatings give a hydrophilic surface for the cementious material this helps in removing solid pollutants in addition to the photochemical reaction. 


\section{References}

1. ASTM:C1437-13, 2013. Standard Test Method for Flow of Hydraulic Cement Mortar 1. ASTM International, pp.1-2.

2. ASTM C305, 2011. Standard Practice for Mechanical Mixing of Hydraulic Cement Pastes and Mortars of Plastic Consistency. ASTM International, pp.1-3.

3. ASTM C778, 2002. Standard Specification for Standard Sand. ASTM International, Vol 14.04.(Reapproved), pp.1-4.

4. Balaguru, P. \& Chong, K., 2008. Nanotechnology and concrete: research opportunities. ACI Special Publication, pp.15-28. Available at: http://www.concrete.org/Publications/GetArticle.aspx?m $=$ icap\&pubID $=20208$.

5. Beeldens, A., 2006. Environmentally Friendly Concrete Pavement Blocks: Air Purification in the Centre of Antwerp. 8th International Conference on Concrete Block Paving, pp.277-284.

6. Boyd, D.R., 2006. The Air We Breathe: An International Comparison of Air Quality Standards and Guidelines. $A$ REPOR T PREPARED FOR THE DAVID SUZUKI FOUNDATION HEALTH AND ENVIRONMENT SERIES BY.

7. Chen, J., Kou, S. cong \& Poon, C. sun, 2011. Photocatalytic cement-based materials: Comparison of nitrogen oxides and toluene removal potentials and evaluation of self-cleaning performance. Building and Environment, 46(9), pp.1827-1833. Available at: http://dx.doi.org/10.1016/j.buildenv.2011.03.004.

8. Chen, J. \& Poon, C. sun, 2009. Photocatalytic construction and building materials: From fundamentals to applications. Building and Environment, 44(9), pp.1899-1906. Available at: http://dx.doi.org/10.1016/j.buildenv.2009.01.002.

9. Demeestere, K. et al., 2008. Heterogeneous photocatalytic removal of toluene from air on building materials enriched with $\mathrm{TiO} 2$. Building and Environment, 43(4), pp.406-414.

10. Drelich, J. et al., 2011. Hydrophilic and Superhydrophilic Surfaces and Materials*. Electronic Publishing, 7(21), pp.9804-9828.

11. Faraldos, M. et al., 2016. Photocatalytic hydrophobic concrete coatings to combat air pollution. Catalysis Today, 259(x), pp.228-236. Available at: http://dx.doi.org/10.1016/j.cattod.2015.07.025.

12. Fujishima, A. \& Zhang, X., 2006. Titanium dioxide photocatalysis: present situation and future approaches. Comptes Rendus Chimie, 9(5-6), pp.750-760.

13. Granqvist, C.G., 2013. 8 - Thin films and nanostructured coatings for eco-efficient buildings. In A. N. F. PachecoTorgal, M. V. Diamanti \& and C.-G. Granqvist, eds. Nanotechnology in Eco-Efficient Construction. p. 161187a. Available at: http://www.sciencedirect.com/science/article/pii/B97808 57095442500087.

14. Guo, M.Z. \& Poon, C.S., 2012. An Effective Way to Incorporate Nano-TiO 2 in Photocatalytic Cementitious Materials. Third International Conference on Sustainable Construction Materials and Technologies. Available at: http://www.claisse.info/Proceedings.htm.

15. Hassan, M.M. et al., 2012. Methods for the application of titanium dioxide coatings to concrete pavement. International Journal of Pavement Research and Technology, 5(1), pp.12-20.

16. Hathway, T.L., 2009. Titanium dioxide photocatalysis: studies of the degradation of organic molecules and characterization of photocatalysts using mechanistic organic chemistry. Iowa State University.

17. Liu, H. et al., 2016. Recent progress in fabrication and applications of superhydrophobic coating on cellulosebased substrates. Materials, 9(3), pp.1-37.

18. Marco, T. De et al., 2013. Use of photocatalytic products for sustainable construction development. Third International Conferences on Sustainable Construction Materials and Technologies.

19. Martinez, T. et al., 2011. Degradation of NO using photocatalytic coatings applied to different substrates: Dégradation de NO en utilisant des revêtements photocatalytiques appliqués sur différents substrats. Building and Environment, 46(9), pp.1808-1816. Available

at: http://www.sciencedirect.com/science/article/pii/S03601 32311000722\%5Cnhttp://www.sciencedirect.com/scienc e?_ob=MImg\&_imagekey=B6V23-52CYKGN-1$11 \&$ _cdi $=5691 \&$ user $=636532 \& \_$pii $=$S0360132311000 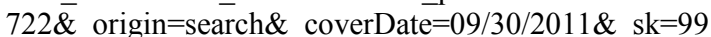 9539990\&view $=c \& w c h p=d$.

20. Rachel, A., Subrahmanyam, M. \& Boule, P., 2002. Comparison of photocatalytic efficiencies of $\mathrm{TiO} 2$ in suspended and immobilised form for the photocatalytic degradation of nitrobenzenesulfonic acids. Applied Catalysis B: Environmental, 37(4), pp.301-308.

21. Ramirez, A.M. et al., 2010. Titanium dioxide coated cementitious materials for air purifying purposes: Preparation, characterization and toluene removal potential. Building and Environment, 45(4), pp.832-838.

22. Zhao, J. \& Yang, X., 2003. Photocatalytic oxidation for indoor air purification: A literature review. Building and Environment, 38(5), pp.645-654. 